\title{
CT diagnosis of appendiceal intussusception in a middle-aged female
}

\author{
Jacob Miller ${ }^{*}$, Savya Shukla ${ }^{1}$, Brian Baigorri ${ }^{1}$, Hilda Tejero ${ }^{1}$ \\ 1. Department of Radiology, Aventura Hospital and Medical Center, Aventura, Fl, USA \\ * Correspondence: Jacob Miller, Department of Radiology, Aventura Hospital and Medical Center, Aventura, Fl, USA \\ (入 Jacob.Miller2@hcahealthcare.com)
}

Radiology Case. 2020 Jun; 14(6):8-14 :: DOI: 10.3941/jrcr.v14i6.3809

\begin{abstract}
Appendiceal intussusception is rare with an estimated incidence of $0.01 \%$. Although it is infrequently encountered, the few documented cases of this entity have shown it may mimic or indicate an underlying neoplasm when evaluated with colonoscopy. With the abundant use of multi-detector CT and increased utility of CT colonography, awareness of the radiologic findings of this condition has become increasingly important. Appendiceal intussusception, while potentially pathologic in its own right, may mimic or even coexist with other pathologies, both malignant and benign. We present a case of adult appendiceal intussusception without a "lead point" that was successfully diagnosed by CT imaging.
\end{abstract}

\section{CASE REPORT}

\section{CASE REPORT}

\section{Clinical history}

A 54-year-old female presented with a weeklong history of worsening right lower quadrant, colicky abdominal pain, and nausea. Physical exam revealed right lower quadrant tenderness. Laboratory analysis was normal.

\section{Imaging findings}

A contrast-enhanced CT of the abdomen and pelvis without oral contrast demonstrated a tubular, sausage-shaped structure within the cecum, separate from the ileocecal valve and ileum. There were no regions of abnormal thickening, inflammatory changes or evidence of necrosis or cystic degeneration. The structure demonstrated smooth peripheral enhancement in continuity with the mucosa of the cecum (figures 1-3).

\section{Management}

The patient was diagnosed with appendiceal intussusception via CT. Her pain improved in the emergency department, and she returned home without incident. The patient was provided an outpatient gastroenterology referral for further management.

\section{DISCUSSION}

\section{Introduction:}

While the overall incidence of appendiceal intussusception (AI) is unknown, the reported incidence among pathologic specimens taken after appendectomy is $0.01 \%$ [1,2]. Many case reports may be found in the gastroenterologic and surgical literature, as it is may be found incidentally during colonoscopy $[3,4,5]$. Although appendiceal pathology was radiographically characterized as early as 1929 , 
the first CT-diagnosed case of AI was not published until 2006 $[6,7]$. With the increased accessibility of multi-detector CT and the advent of CT colonography, it is increasingly important that radiologists be aware of the findings indicative of AI. Knowledge of this entity may assist in reduction of costly and potentially harmful investigative measures such as colonoscopy.

\section{Etiology \& Demographics:}

Suggested anatomic and physiologic risk factors for AI include persistence of a fetal, wide-based appendix or abnormal peristalsis within the appendix and adjacent cecum [1]. AI may present at any age but is more common in adults. Adult females are twice as likely to develop the condition as adult men, though pediatric cases are more likely to occur in males [3]. It is estimated that over $70 \%$ of cases are associated with "lead points" such as endometriosis, adenomas, mucoceles, adenocarcinomas, and various other benign and malignant lesions [1]. Conversely, over $25 \%$ of adult cases and over $75 \%$ of pediatric cases may be solely associated with idiopathic inflammatory changes such as lymphoid follicular hyperplasia and hyperemia without a causative lesion [3]. It has been proposed that patients at increased risk for intestinal intussusception from certain gastrointestinal pathologies, such as Crohn's disease or cystic fibrosis, may be at higher risk of developing AI $[8,9]$.

\section{Clinical \& Imaging Findings:}

While many patients are asymptomatic, others may present with waxing and waning abdominal pain. Less often, patients may present with vomiting, diarrhea, or hematochezia. Physical exam often elicits tenderness, though an abdominal mass may be palpated [3]. There is no imaging finding which has been shown to predict whether appendiceal intussusception is symptomatic.

Barium enema will demonstrate a small "coiled-spring" appearance in the cecum from contrast between the intussusceptum (appendix) and intussuscipiens (cecum) (figure 4). The appendix will not be visualized until reduction. Contrast may be seen refluxing into a normal-appearing ileum [10]. Ultrasound may demonstrate the classic "target" or "donut" appearance of intussusception in the cecum, with concentric hyperechoic and hypoechoic layers of bowel wall on perpendicular images [3,11] (figure 5). Rarely, AI "lead points" such as endometrial implants may be characterized on ultrasound as a hypoechoic nodule with posterior shadowing (figure 6). While ultrasound may be the initial modality of choice to evaluate for appendiceal intussusception in certain populations due to lack of ionizing radiation, the limitations of ultrasound are likely to prompt further investigation. These limitations include inter-user variability, and the potential for artifact from bowel gas to obscure this finding. AI will appear on CT as a targetoid lesion in the cecum on images perpendicular to the long axis of the intussusception, and a "sausage-shaped" or "reniform" structure on images parallel to the intussusception [6]. The mucosa may demonstrate smooth enhancement, though enhancement pattern will vary with the presence and type of "lead point." For example, endometriosis may demonstrate nodular mucosal enhancement. The MRI characteristics of AI will be similar to those demonstrated in CT. Additional information such as signal characteristics indicating cellularity, edema, and mucous may assist in the characterization and potential staging of an appendiceal "lead point." For example, MRI may detect extraluminal mucin in mucinous appendiceal neoplasms or delayed gadolinium enhancement in mucinous appendiceal adenocarcinoma.

\section{Differential diagnosis:}

The differential diagnosis for a cecal mass includes an inverted post-operative appendix, ileocolic intussusception, a cecal polyp, fecal debris, and an inverted colonic diverticulum.

\section{Postoperative appendix}

Careful correlation with the patient's medical and surgical history should guide the radiologist to the accurate diagnosis of AI. There are two obscure surgical techniques which may mimic AI: "dunking," of the appendiceal stump using a pursestring suture after appendiceal ligation, or deliberate inversion of the appendix altogether for treatment of appendicitis [12]. Knowledge of the patient's surgical history is essential in the differentiation of AI with the post-operative appendix, as these entities may appear nearly identical to appendiceal intussusception on barium enema, ultrasound, CT, and MRI.

\section{Ileocecal intussusception}

Ileocecal intussusception may demonstrate a large "coiled-spring" sign on barium enema, but reflux may not occur into the ileum until reduced. Due to the lack of anatomic landmarks, AI may be easily confused with ileocecal intussusception on sonography. It demonstrates a classic targetoid appearance, with concentric hyperechoic and hypoechoic layers of bowel wall on perpendicular images (figure 5) [3,11]. Ileocecal intussusception is best differentiated from AI on CT. The large, "sausage-shaped" intussusceptum will arise from the ileum. The enhancement pattern may be similar. However, instances of ileocecal intussusception mimicking or even arising with AI have been reported [11, 13] (figure 5). Referencing reformatted images as well as correlation with other modalities may assist in excluding $\mathrm{AI}$ in these cases.

\section{Colonic polyp}

The classic fluoroscopic appearance of colonic polyps is the "Mexican hat" sign of a pedunculated polyp and the "bowler hat" of a sessile polyp [14]. A polyp will demonstrate a hypoechoic mass with variable morphology as well as internal vascularity on ultrasound [15]. On CT, polyps demonstrate variable morphology, though most advanced adenomas are large $(>10 \mathrm{~mm})$, with a pedunculated or sessile appearance. Most polyps are hypodense with enhancement patterns that will vary with the polyp type [16]. Special note should be made of an inverted mucocele arising from an appendiceal stump. A mucocele arising from an inverted stump will appear as a "tubular" or "spherical" cystic mass and may demonstrate peripheral calcifications on CT, and could conceivably be confused for an inverted appendix. Any enhancing soft tissue component or wall irregularity of an 
appendiceal mucocele should prompt further investigation [17].

\section{Fecal material}

Fecal material in the cecum may produce filling defects on barium enema but should be mobile and discontinuous with the cecum. Fecal material is easily differentiated from AI on ultrasound, as it demonstrates internal gas foci and lacks the vascularity and targetoid appearance of AI. On CT, retained fecal debris in the cecum will appear irregular and discontinuous with the cecal lumen. Foci of air and contrast may be seen.

\section{Inverted colonic diverticulum}

An inverted colonic diverticulum is a rare entity that may mimic colonic polyps and was first fluoroscopically described in the cecum. On barium enema, it was demonstrated as a "smooth, polypoid mass" [18]. Inverted colonic diverticuli are poorly characterized in other modalities due to their rarity.

\section{Treatment \& Prognosis:}

Management of asymptomatic intussusception is not well understood. Further evaluation with direct visual inspection should be considered in cases where appendiceal "lead point" is suspected.

While no guidelines exist for the management of symptomatic AI, treatment options include barium or air enema reduction, colonoscopic reduction, and surgical intervention. The radiologist should carefully consider possible contraindications such as malignant spread of disease from peritoneal seeding or bowel perforation in those with appendiceal neoplasms or signs of bowel ischemia before recommending colonoscopic reduction or performing barium enema [5,19]. If reduction is successful, nonoperative management and repeat reduction may be considered in recurrent cases [3]. Alternatively, appendectomy may be performed for benign, symptomatic appendiceal intussusception amenable to reduction. If reduction is unsuccessful, a more extensive resection such as partial caecectomy and appendectomy, may be performed $[4,6]$. In cases where appendiceal intussusception occurs with malignancy, right hemicolectomy may be performed. Prognosis will depend on the intervention performed as well as presence and type of "lead point."

\section{Conclusion:}

AI is a rare entity with presentations that range from transient, colicky abdominal pain, to acute, severe abdominal pain and hematochezia. It may be asymptomatic and incidental, though care should be taken to exclude "lead point" pathology, particularly in the adult population. Correlation with surgical history and different imaging modalities may assist in the accurate diagnosis of this entity. If excision is required for treatment, preoperative reduction may be considered in patients without bowel ischemia or malignancy.

\section{TEACHING POINT}

Appendiceal intussusception is a rare entity, which appears on CT as a "sausage-shaped," or "reniform" lesion in the cecum. Appendiceal intussusception has variable symptomatology, but may be precipitated by a "lead point" in adults, which should prompt further investigation.

\section{REFERENCES}

1. Baleáto-Gonzlez S, Vilanova JC, García-Figueiras R, Juez IB, and Martinez de Alegría A. Intussusception in adults: what radiologists should know. Emergency Radiology. 2011; 19: 89-101. PMID: 22200965.

2. Collins DC. 71,000 human appendix specimens. A final report summarizing forty years' study. American Journal of Proctology. 1963;14:265-281. PMID: 14098730.

3. Ochoa Charr CI, Wexelman B, Zuckerman K, and Longo W. Intussusception of the appendix: comprehensive review of the literature. The American Journal of Surgery. 2009; 198: 122-128. PMID: 19249733

4. Ashrafi M, Joshi V, Zammit M, and Telford K. Intussusception of the appendix secondary to mucinous cystadenoma: a rare cause of abdominal pain. International Journal of Surgery Case Reports. 2010; 2(2): 26-27. PMID: 22096680

5. Park JK, Tae HK, Hyun KK, Jeong BP, Kank K, and Jeong IS. Adult intussusception caused by an appendiceal mucocele and reduced by colonoscopy. Clinical Endoscopy. 2011; 44: 133-136. PMID: 22741125.

6. Luzier J, Verhey P, and Dobos N. Preoperative CT diagnosis of appendiceal intussusception. American Journal of Roentgenology. 2009; 187:W325-6. PMID: 6928915.

7. Demos TC and Filsak ME. Coiled-spring sign of the cecum in acute appendicitis. American Journal of Roentgenology. 1986;146: 45-48. PMID: 3484408.

8. Cappell MS, Lajin M, and Amim M. Colonoscopic findings in appendiceal intussusception in cystic fibrosis: a tubular cecal structure containing impacted luminal secretions. Clinical Gastroenterology and Hepatology. 2010; 8(12):A278. PMID: 20621198.

9. Aybay MN, Erol S, Kaya HE, and Guler I. Appendix invagination mimicking ileocecal intussusception in a pediatric patient: a case report. The Journal of Emergency Medicine. 2016; 15(5):585-591. PMID: 27623217.

10. Levine MS, Trenkner SW, Herlinger H, Mishkin JD, and Reynolds JC. Coiled-spring sign of appendiceal intussusception. Radiology. 1985; 155(1): 41-44. PMID: 3975417.

11. Komanidou C, Vakaki M, Theofanopoulou M, Nikas J, Pitsoulakis G, and Kakavakis K. Appendiceal and 
appendiceal-ileocolic intussusception: sonographic and radiographic evaluation. Pediatric Radiology. 2001; 31: 180183. PMID: 11297082.

12. Johnson EK, Arcila ME, and Steele SR. Appendiceal inversion: a diagnostic and therapeutic dilemma. Journal of the Society of Laparoendoscopic Surgeons. 2009; 13:92-95. PMID: 19366551.

13. Iqbal CW, Kamath AS, and Zietlow SP. Appendiceal intussusception masquerading as ileocolic intussusception. Journal of Gastrointestinal Surgery. 2012; 16:1076-1077. PMID: 22370734.

14. Levine MS, Rubesin SE, Laufer I, and Herlinger $\mathrm{H}$. Diagnosis of colorectal neoplasms at double-contrast barium enema examination. Radiology. 2000; 216 11-18. PMID:10887222.

15. Yabunaka K, Sanada S, Fukui H, Tamate S, and Fujioka M. Transabdominal sonographic appearance of adult colonic polyps. Journal of Medical Ultrasonics. 2006;33(4):231-237. PMID: 27277980.

16. Kim DH, Pickhardt PJ, and Taylor AJ. Characteristics of advanced adenomas detected at CT colonographic screening: implications for appropriate polyp size thresholds for polypectomy versus surveillance. American Journal of Roentgenology. 2007; 188:940-944. PMID: 17377027.

17. Van Hooser A, Williams TR, and Myers DT. Mucinous appendiceal neoplasms: pathologic classification, clinical implications, imaging spectrum and mimics. Abdominal Radiology. 2018; 43:2913-2922. PMID: 29564494

18. Freeny PC and Walker JH. Inverted diverticula of the gastrointestinal tract. Gastrointestinal Radiology.1979; 4(1):57-59. PMID: 761745.

19. Omori H, Asahi H, Inoue $Y$, Irinoda T, Takahashi M, and Saito K. Intussusception in adults: a 21-year experience in the university-affiliated emergency center and indication for nonoperative reduction. Digestive Surgery. 2003; 20(5):433439. PMID: 12900535.

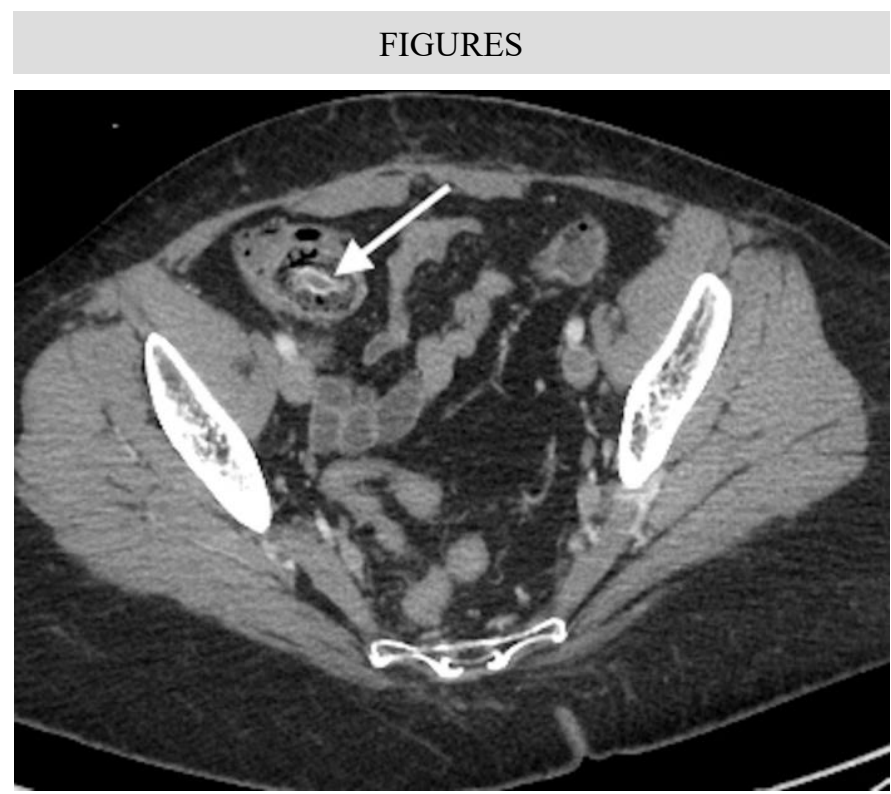

Figure 1: 54-year-old female with appendiceal intussusception. Findings: Axial contrast-enhanced CT of the pelvis demonstrates an $8 \mathrm{~mm}$, "targetoid" lesion within the cecum with strong mucosal enhancement. Technique: Axial CT. $419 \mathrm{mAs}, 120 \mathrm{kV}, 2 \mathrm{~mm}$ slice thickness, $100 \mathrm{~mL}$ Isovue 300 .

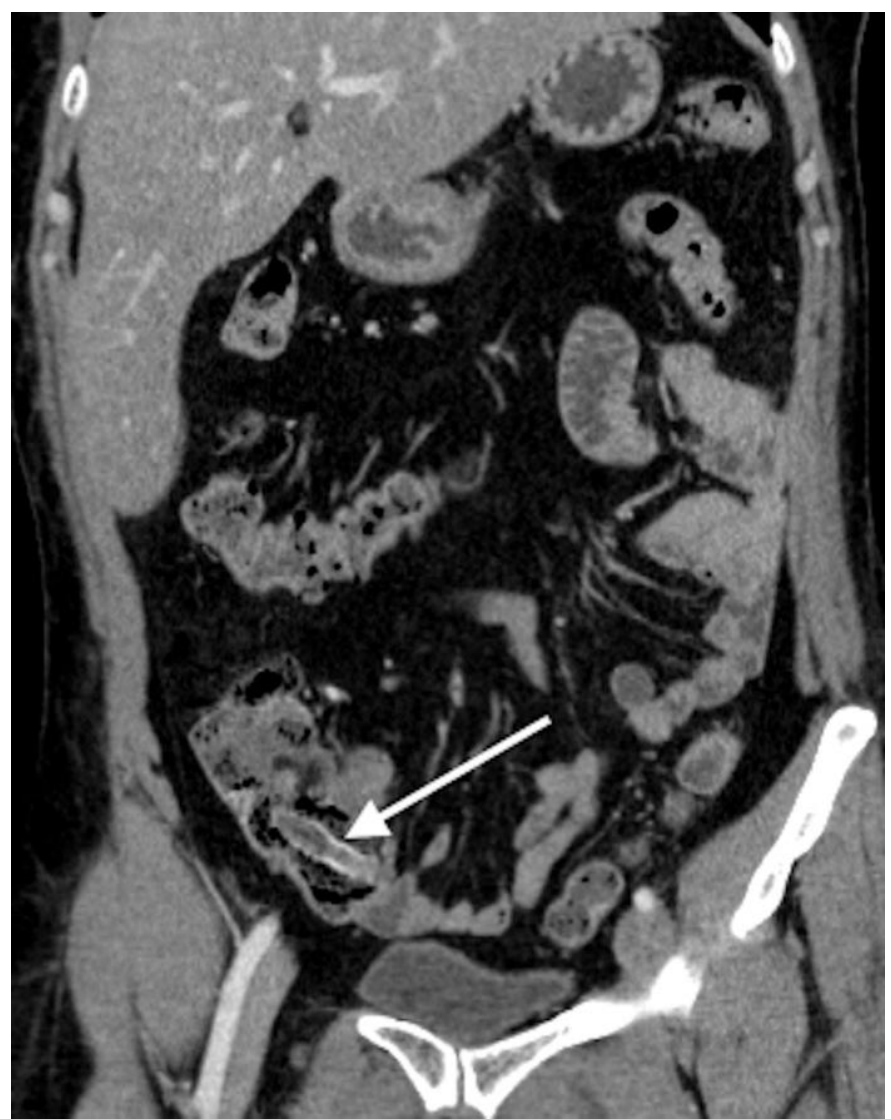

Figure 2: 54-year-old female with appendiceal intussusception. Findings: Coronal contrast-enhanced CT of the pelvis demonstrates an 8 x $43 \mathrm{~mm}$, "sausage-shaped" lesion within the cecum with strong mucosal enhancement, contiguous with the cecal mucosa. Note the normal-appearing ileum, separate from the lesion. Technique: Coronal CT, 419 mAs, $120 \mathrm{kV}, 2 \mathrm{~mm}$ slice thickness, $100 \mathrm{~mL}$ Isovue 300 . 


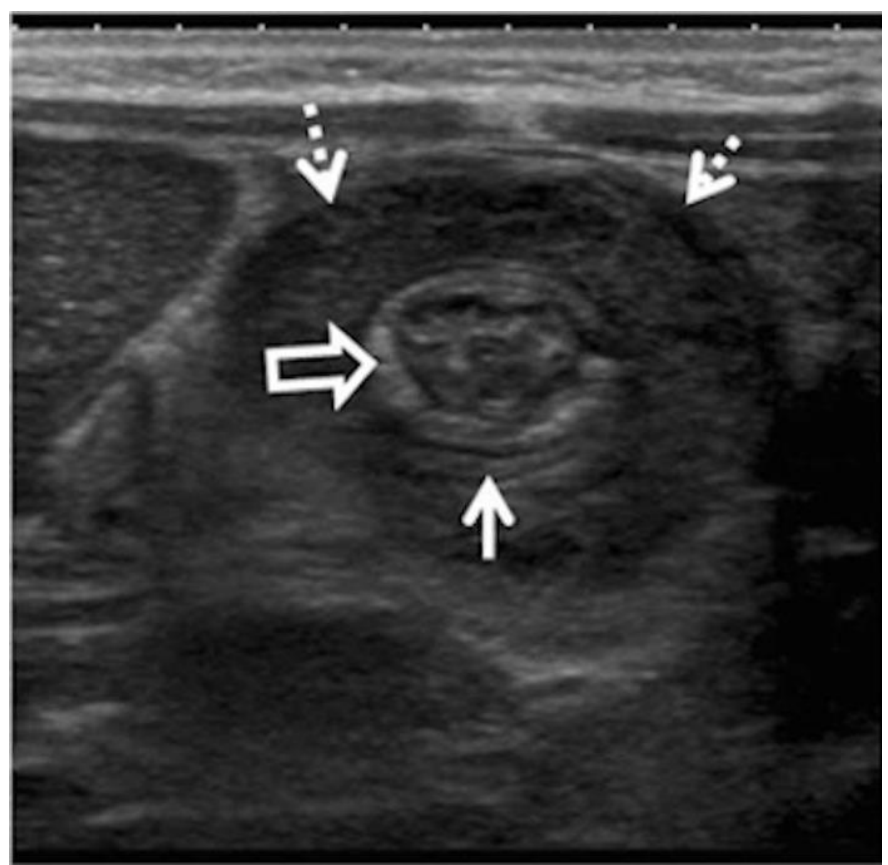

Figure 5: Intussusception of the appendix in a 13-month-old boy. Findings: Transverse ultrasound demonstrates ileocolic intussusception (dashed arrows) with a classic target appearance. A tubular structure suggestive of a normal appendix (solid arrow) is seen in the intussusceptum (open arrow). Technique: Ultrasound of the right lower abdomen using a $7 \mathrm{MHz}$ linear array with graded compression. (Reprinted by permission: Dietz et al. Beyond acute appendicitis: imaging of additional pathologies of the pediatric appendix. Pediatr Radiol. 2013 Jan;43(2):232-42.)

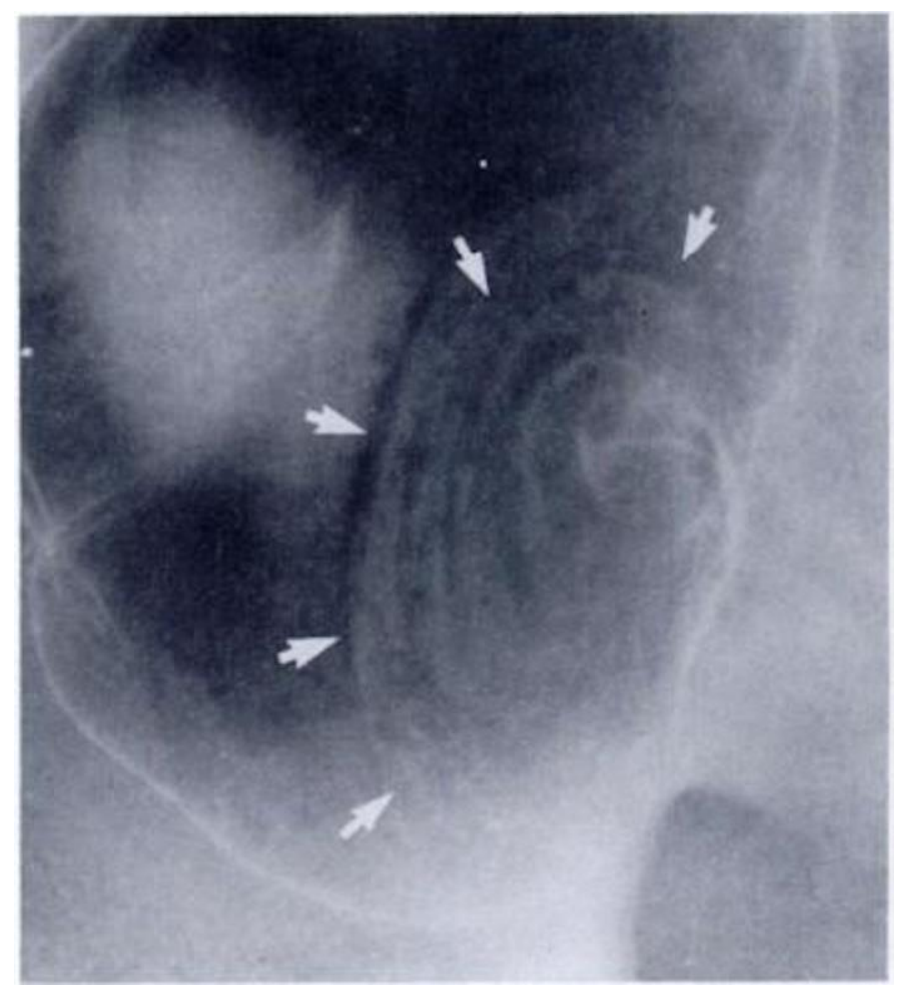

Figure 4 (left): Transient appendiceal intussusception in an asymptomatic patient. Findings: Spot radiograph from double contrast barium enema reveals a coiled-spring defect in cecum (arrows) with nonfilling of the appendix. Technique: Frontal, magnified radiograph of the right lower abdominal quadrant using intraluminal barium contrast and air. kVp 90; mAs 40. (Reprinted by permission: Levine MS, Trenkner SW, Herlinger $\mathrm{H}$, et al. Coiled-spring sign of appendiceal intussusception. Radiology. 1985; 155:41-44.) 


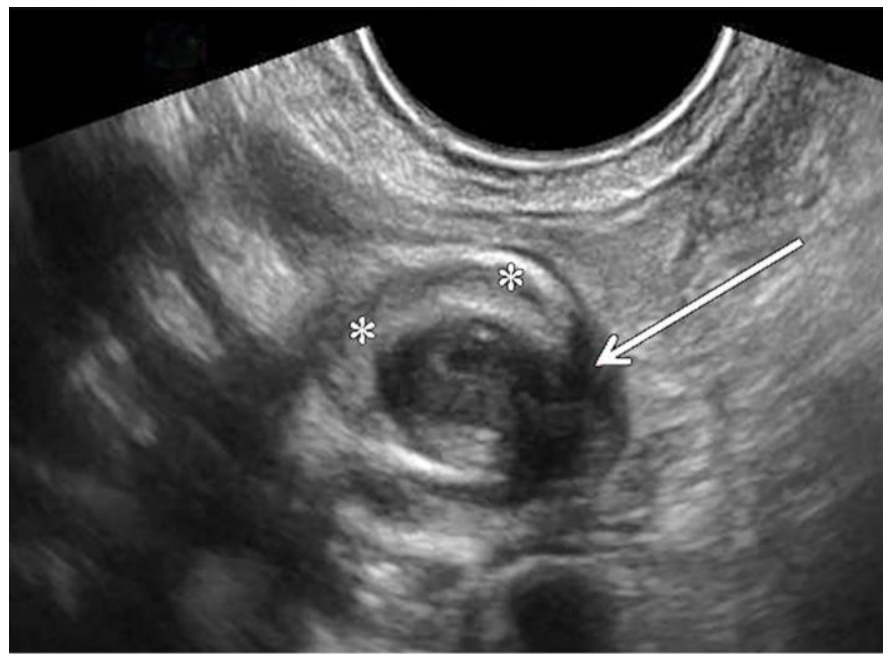

Figure 6 (left): 39-year-old woman with appendiceal intussusception secondary to endometriosis. Findings: Transvaginal ultrasound of the right iliac fossa demonstrates a hypoechoic nodule with posterior shadowing (arrow). Adjacent to this nodule is the appendix, invaginated centrally within the cecum (asterisks). Technique: Transvaginal ultrasound using $7 \mathrm{MHz}$ endocavity, curvilinear probe. (Reprinted by permission: Chamié LP, Ribeiro DMRF, Tiferes DA, et al. Atypical sites of deeply infiltrative endometriosis. Clinical characteristics and imaging findings. Radiographics 2018;38:309-328.)

\begin{tabular}{|l|l|}
\hline Etiology & $\begin{array}{l}\text { Not completely understood } \\
\text { Anatomic and physiologic factors wide-based appendix and abnormal peristalsis } \\
\text { "Lead points" }(>70 \%) \text { : endometriosis, mucoceles, adenomas, adenocarcinomas, and other } \\
\text { neoplasms }\end{array}$ \\
\hline Incidence & $0.01 \%$ \\
\hline Gender ratio & $\begin{array}{l}\text { Greater than } 2: 1 \text { female to male predilection } \\
\text { In children, males are more likely to be affected }\end{array}$ \\
\hline Age predilection & $\begin{array}{l}\text { Most common in adults (76\%) } \\
\text { No age cut-offs established }\end{array}$ \\
\hline Risk factors & Anatomic/physiologic risk factors as above. Cystic fibrosis and Crohn's disease. \\
\hline Treatment \& Prognosis & $\begin{array}{l}\text { Asymptomatic cases: evaluate with colonoscopy as indicated. } \\
\text { Symptomatic cases: therapeutic enema reduction and/or resection. } \\
\text { "Lead point" associated cases: resection with or without preoperative reduction. } \\
\text { No rate of recurrence is established after reduction. } \\
\text { Prognosis depends on intervention performed. } \\
\text { Concurrent malignancies will require different treatments and have different prognoses. }\end{array}$ \\
\hline Findings on imaging & $\begin{array}{l}\text { Barium enema: Small "coiled spring" sign } \\
\text { Ultrasound: "Donut" or "target" sign } \\
\text { CT: “Targetoid" appearance on transverse images and a "sausage-shaped" appearance on } \\
\text { longitudinal orientations. This structure will demonstrate continuity with the cecum. Ileum should } \\
\text { be normal in location. Normal appendix will be absent. }\end{array}$ \\
\hline
\end{tabular}

Table 1: Summary table for appendiceal intussusception. 


\begin{tabular}{|c|c|c|c|c|c|}
\hline Differential Diagnosis & Barium enema & Ultrasound & CT & MRI & Enhancement \\
\hline $\begin{array}{l}\text { Appendiceal } \\
\text { intussusception }\end{array}$ & $\begin{array}{l}\text { "Coiled spring" with } \\
\text { no demonstrable } \\
\text { appendix. }\end{array}$ & $\begin{array}{l}\text { "Doughnut } \\
\text { sign" with no } \\
\text { demonstrable } \\
\text { appendix. }\end{array}$ & $\begin{array}{l}\text { Axial: targetoid } \\
\text { Coronal/sagittal: } \\
\text { "Sausage shaped" or } \\
\text { "reniform" lesion in } \\
\text { the cecum. The } \\
\text { appendiceal wall is } \\
\text { often edematous. }\end{array}$ & $\begin{array}{l}\text { Will depend on the } \\
\text { "lead point," which } \\
\text { if present, will } \\
\text { demonstrate the } \\
\text { typical } \\
\text { characteristics of } \\
\text { the entity. }\end{array}$ & $\begin{array}{l}\text { Normal enhancement of } \\
\text { the mucosal lining of } \\
\text { the appendix, or } \\
\text { enhancement } \\
\text { commensurate with that } \\
\text { of the pathologic "lead } \\
\text { point," if present. }\end{array}$ \\
\hline $\begin{array}{l}\text { Postoperative } \\
\text { appearance of } \\
\text { inversion-ligation }\end{array}$ & \multirow{2}{*}{\multicolumn{5}{|c|}{$\begin{array}{l}\text { Findings will be essentially identical to appendiceal intussusception, with a positive history of appendectomy. } \\
\text { Postoperative changes of the abdominal wall may assist in diagnosis, if history is unknown. }\end{array}$}} \\
\hline $\begin{array}{l}\text { Postoperative } \\
\text { appearance of simple } \\
\text { inversion }\end{array}$ & & & & & \\
\hline Fecal matter & $\begin{array}{l}\text { Normal filling of the } \\
\text { appendix, filling } \\
\text { defects discontinuous } \\
\text { with cecum. Mobile. }\end{array}$ & $\begin{array}{l}\text { Presence of } \\
\text { appendix. } \\
\text { Absence of cecal } \\
\text { lesion with "gut } \\
\text { signature." }\end{array}$ & $\begin{array}{l}\text { Presence of a normal } \\
\text { appendix. } \\
\text { Discontinuity of the } \\
\text { lesion with the cecal } \\
\text { wall. }\end{array}$ & $\begin{array}{l}\text { Presence of a } \\
\text { normal appendix. } \\
\text { Signal intensities } \\
\text { consistent with } \\
\text { stool }\end{array}$ & $\begin{array}{l}\text { No enhancement and } \\
\text { presence of normal } \\
\text { appendix. }\end{array}$ \\
\hline $\begin{array}{l}\text { Ileocecal } \\
\text { intussusception }\end{array}$ & $\begin{array}{l}\text { Normal filling of } \\
\text { appendix. A larger } \\
\text { "coiled spring" sign. }\end{array}$ & $\begin{array}{l}\text { Presence of } \\
\text { appendix with } \\
\text { intra-cecal } \\
\text { "targetoid } \\
\text { lesion" } \\
\text { containing "gut } \\
\text { signature" }\end{array}$ & $\begin{array}{l}\text { Presence of normal } \\
\text { appendix. A large } \\
\text { "sausage-shaped, } \\
\text { "reniform," or } \\
\text { "targetoid" lesion may } \\
\text { be seen in the cecum. }\end{array}$ & $\begin{array}{l}\text { Presence of } \\
\text { normal appendix. } \\
\text { Will depend on } \\
\text { "lead point," which } \\
\text { if present, will } \\
\text { demonstrate the } \\
\text { typical } \\
\text { characteristics of } \\
\text { the entity. }\end{array}$ & $\begin{array}{l}\text { Normal to slightly } \\
\text { decreased wall } \\
\text { enhancement of } \\
\text { intussusceptum. }\end{array}$ \\
\hline Cecal polyp & $\begin{array}{l}\text { Radiolucent filling } \\
\text { defects including } \\
\text { "Bowler hat sign," } \\
\text { "Mexican hat sign," } \\
\text { and "carpet lesion" } \\
\text { with normal filling of } \\
\text { the appendix. }\end{array}$ & $\begin{array}{l}\text { A spherical or } \\
\text { ovoid } \\
\text { hypoechoic } \\
\text { lesion with } \\
\text { internal vascular } \\
\text { components. } \\
\text { Presence of } \\
\text { appendix. }\end{array}$ & $\begin{array}{l}\text { "Pedunculated," or } \\
\text { "sessile" hypodense, } \\
\text { solid lesion distinct } \\
\text { from the normal } \\
\text { appendix. }\end{array}$ & $\begin{array}{l}\text { Signal intensities } \\
\text { reflecting } \\
\text { components of a } \\
\text { polyp. i.e. } \\
\text { cellularity, } \\
\text { mucous, or edema. } \\
\text { Normal appendix. }\end{array}$ & $\begin{array}{l}\text { Heterogeneous } \\
\text { enhancement. }\end{array}$ \\
\hline $\begin{array}{l}\text { Inverted colonic } \\
\text { diverticulum }\end{array}$ & $\begin{array}{l}\text { "Smooth polypoid } \\
\text { mass" }\end{array}$ & $\begin{array}{l}\text { No characteristic } \\
\text { imaging finding } \\
\text { for this modality }\end{array}$ & $\begin{array}{l}\text { No characteristic } \\
\text { imaging finding for } \\
\text { this modality }\end{array}$ & $\begin{array}{l}\text { No characteristic } \\
\text { imaging finding for } \\
\text { this modality }\end{array}$ & Not established. \\
\hline
\end{tabular}

Table 2: Differential diagnosis table for appendiceal intussusception.

\section{ABBREVIATIONS}

$\mathrm{AI}=$ Appendiceal intussusception

$\mathrm{CT}=$ Computed tomography

MRI = Magnetic resonance imaging

\section{KEYWORDS}

Appendiceal intussusception; Appendix inversion; Computed tomography; Gastrointestinal radiology; Appendix

\section{Online access}

This publication is online available at:

www.radiologycases.com/index.php/radiologycases/article/view/3809

\section{Peer discussion}

Discuss this manuscript in our protected discussion forum at: www.radiolopolis.com/forums/JRCR

\section{Interactivity}

This publication is available as an interactive article with scroll, window/level, magnify and more features.

Available online at www.RadiologyCases.com

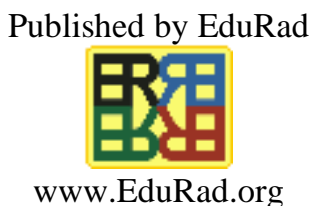

